\title{
Frontiers in Comparative Metrics III, 29-30 September 2017, Tallinn, Estonia
}

\section{Kadri Novikov, Anni Arukask}

On 29-30 September 2017, a conference titled Frontiers in Comparative Metrics III was held at Tallinn University. The first conference in this series was held in 2008 in memory of Mikhail Gasparov, and the second in 2013 in memory of Lucylla Pszczołowska. This year's conference was dedicated to the 75th anniversary of the eminent Estonian scholar, Jaak Põldmäe, who was the founder of scientific Estonian verse theory. The conference hosted numerous scholars from all over the world, who discussed various aspects of metrics and prosody.

The conference was opened by Mihhail Lotman, who gave an overview of the life of Jaak Põldmäe and his importance to Estonian versification studies. Jaak Põldmäe was born in 1942 in Tartu, but deported to Siberia at the age of seven. In 1955 his family was allowed to return to Estonia and Põldmäe started his studies at the University of Tartu, where he became acquainted with the Russian statistical methods for studying versification; yet his academic supervisor, Vyacheslav V. Ivanov, inspired him to work with the axiomatic approach to versification systems. Põldmäe's monography about Estonian verse is theretofore the most thorough treatment written on this subject. After graduating Põldmäe taught at the University of Tartu until his death in 1979. His works and ideas, however, were often criticised by other scholars of Estonian verse, though admired internationally.

Both days of the conference started with keynote lectures. On the first day, Marina Tarlinskaja, of the University of Washington, presented a paper (in cooperation with Darren Freebury-Jones, Cardiff University, and Marcus Dahl, the Institute of English Studies) about determining the authorship of the late Elizabethan-early Jacobean playwright John Marston. As the plays at that time were often written in co-operation, it is difficult to attribute several plays to one or another author. Marina Tarlinskaja, Darren Freebury-Jones and Marcus Dahl have been analysing spelling idiosyncrasies, vocabulary frequency, recurring collocations, and numerous versification features of four texts in John Marston's canon, where his authorship is not certain: Lust's Dominion (1600), Histriomastix (1602), The Family of Love (1607), and The Insatiate Countess (1610). They compared the plays with Antonio and Mellida - a play certainly written by Marston - and Thomas Dekker's The Honest Spanish Soldier. The results showed that Histriomastix (1602) and The Insatiate Countess (1610) 
were most probably written by Marston, whereas Lust's Dominion seems to be written by Dekker. The authorship of The Family of Love remained uncertain.

Geoffrey Russom (Brown University) discussed the relations of the optimality theory and poetic form in three major language types: SubjectObject-Verb (early Germanic), Subject-Verb-Object (Modern English), and Verb-Subject-Object (Old Irish). He showed how the well-formedness rule is more important in metrical structure, changes appear rather on the linguistic level than in the metrical patterns, resolving sometimes e.g. in archaisms even after considerable language changes. Faithfulness rules are metrically irrelevant, but well-formedness rules have effects that are registered by the principle of closure, which inhibits departures from optimal form toward the end of a metrical unit.

Bruno Paoli (Lumière University Lyon 2) offered a new approach to analysing Arabic metrics in addition to al-Halil's classical theory, one which does not consider the actual practice of Arab poets. Bruno Paoli introduced an analysis based on the poetry of the 5 th, 6 th and 7 th centuries of the $\mathrm{CE}$, demonstrated the main verse-patterns employed by the poets, and concluded that a certain number of principles governed the internal organization of the poems of this period. He emphasised how the metrical analysis must regard four levels external, internal, historical and comparative - in order to make theoretical interpretations and modelizations of versification types.

Chris Golston (California State University, Fresno) proposed that it is possible to reconstruct a Proto Indo-European quantitative tetrameter of 16 moras. He used the examples of four early Indo-European meters (Greek, Sanskrit, and Old English) as evidence: anapestic tetrameter from Greek drama, a family of meters called 'trochaic tetrameter' in classical Sanskrit, the āryās of Sanskrit and Prakrit, and the alliterative verse of Old English.

The following papers were presented in eight sessions during the two days of conference. Session I started with the paper by Peter Grzybek (University of Graz), who discussed the relations between the decasyllable used in South Slavonic epic songs (deseterac, occurring as the male-deseterac with a caesura after the fourth syllable and the female-deseterac with a caesura after the fifth syllable) and the length of words used in the lines of this meter. He focused on the possibility of constructing a theoretical model of deseterac based on the frequencies of word lengths and the frequencies of certain word length sequences, as well as the patterns of word lengths in epic songs and their specific position within individual lines. In addition, the question of how that model relates to Serbian and Croatian prose texts was examined. Michael Vignola (UCLA) explored the influences of Anglo-Saxon poetics in the poems by Richard Wilbur, concentrating on his poem "Junk", which can be regarded as a formal 
and thematic adaption of the Anglo-Saxon fragment Waldere. Wilbur imitated the complex stress patterns and alliteration and transferred the Anglo-Saxon attitude toward material objects to the 20th-century American consumer culture. Vignola also discussed the problems of adapting the Old English poetics to Modern English in general. Finally, Mirella De Sisto (Meertens Institute) compared the French alexandrine and its adaption into Dutch poetry during the Renaissance period. Their common feature is the caesura, which is always present in French and usually in Dutch versions; however, the French alexandrine is divided into cola with one prominent position, while the Dutch version is iambic-foot-based and has a clear stressed-unstressed sequence. De Sisto supposed that the difference is due to phonological structures: in French the predominant prosodic level is the phonological phrase with the main stress at its right edge (=colon), but in Dutch it is the phonological word which has a word-stress (=foot).

Session II started with the paper by Donka Minkova (UCLA), who discussed the different ways of marking the right-edge of prosodic domains in Old, Middle and Present-Day English. She introduced her project, which examines whether some testable prosodic and segmental signs of such boundaries in Present-Day English help to clarify two questions concerning Old and Middle English alliterative verse: 1) how can the apparent violations of Kaluza's Law be explained; and 2) how does the "rule", that every b-verse of the Middle-English alliterative verse requires a single unstressed syllable at the end, correspond to the right-edge prosodic and metrical weight. Megan Hartman (University of Nebraska at Kearney) explored the hypermetric tools in the Old Saxon Heliand, where the poet expands the average length of lines and employs them throughout the poem in new ways. He uses hypermetric meter also in single lines or individual verses, whereas the Old English used it in extended groupings of verses. Hartman examined why the Heliand poet divided the verses in such a novel way and discussed the different poetic effects and semantic uses of the lone lines in contrast to longer groupings. Teresa Proto (Leiden University Center for Linguistics) spoke about the most widely used meter both in Italian literary and oral traditions - the endecasillabo. The oral and sung endecasillabi are often irregular in form, the latter displays a double structure combined with music. Proto brought out the similarities and differences in the structure and performance of the sung and spoken endecasillabo from the standpoint of two tenants in current metrical theory and typology: verse to delivery and design to instances (Jakobson 1960), and prosodic metrics to isochronous metrics (Aroui 2009). She examined the possibilities for conciliating these two opposing views. 
In session III, Anastasia Belousova (Lomonosov Moscow State University; Universidad Nacional de Colombia) showed in her presentation what kind of (metrical, rhythmical and especially syntactic) changes occurred when the Italian terza rima was adopted into Russian poetry, both in translations of Dante and in original poetry. The presentation also focused on the semantic transformations, or the process of "nationalization" (="domestication") of this stanza in time. The same subject was discussed in the paper by Anastasia Belousova, Svetlana Bochaver, and Vera Polilova (all of Lomonosov Moscow State University), where they introduced the process of creating a digital database of the interlingual transfer of Romance verse forms into Russian poetry. The database will contain the collections of texts divided into translated and original texts, texts written using Romance poetic forms, and texts including elements of Romance languages. The metrical and stanzaic markup of the texts in the database (e.g. Russian terza rima, alexandrin etc.) will enable search and data analysis. Vera Polilova continued with examining the origin, functioning and semantics of the Spanish trochaic tetrameter in Russian literature, which was adopted from German literature. The focus of the paper was on the process of canonization of the Spanish trochaic meter and its functioning in conjunction with the genre of Spanish romance in Russian literature, as compared to the history of this genre and its descendants in Europe. The last speaker at session III was Rebekka Lotman (Tallinn University), who gave a diachronic overview of the incidence of Estonian sonnet as the most popular fixed form in Estonian poetry. In addition, she outlined the various formal patterns (rhyme schemes and meter) used in sonnets, determined when the most experimental period in its history was, and examined whether the sonnets written in free world and in Soviet Estonia differ in form.

Jeremy Scott Ecke (University of Arkansas at Little Rock) began Session IV with a discussion of the phenomenon of concatenation or phrasal linking in Middle Scott and Middle English stanzaic alliterative compositions. Such linking occurs both within stanzas, between shorter wheel lines and the half-lines of the longer alliterative lines, as well as between stanzas. It also provides strong evidence for the foundational constituents of the metrical and prosodic hierarchies treated and advanced in later generative models of metrical form. Mari Sarv (Estonian Literary Museum) spoke about the Estonian indigenous singing tradition, called runosong, which acquired a special position as one of the representatives of Estonian national culture during the awakening of national identity. This meter was also used in literature (the national epic Kalevipoeg by Fr. Kreutzwald) serving as the ideological connection to Estonian ancient "high culture". These ideological influences can also be noticed in theoretical research of this meter, as well as in metrical varieties 
depending on the topics of the songs. The differences were demonstrated by singing at the end of the presentation. Singing played a part also in the presentation by Jacqueline Ekgren by demonstrating the structure of poetry and music with "free rhythm". The focus of the paper was on the Norwegian stev a living tradition of the sung accentual poetry, which uses paired rhythmic patterns, which seem irregular, yet are predictable in closer examination. The paired rhythmic events are used also in other old Germanic poetical works.

In Session V, Kevin Ryan (Harvard University) argued that the final strictness in metrical units is not as solid as commonly regarded. He proposes that the explanation for final strictness is final strength: in traditions with final strictness, right branches are more prominent than left branches above the prosodic word. The analysis of Kamban's epic, the Tamil language, having head-initial phonological phrases or intonation groups, shows rather initial strictness of metrical units. Tatyana Skulacheva (Vinogradov Institute of Russian Language of the Russian Academy of Sciences) and Alexander Kostyuk (Lomonosov Moscow State University) presented a joint paper analysing various regularities at different levels of linguistic structure in verse and prose and their influence on the human brain. Several experiments show how linguistic mechanisms found may be responsible for intensifying imaginative thinking at the expense of logical. Petr Plecháć (Institute of Czech Literature of the Academy of Sciences of the Czech Republic), Klemens Bobenhausen (Pearl Communication \& Consulting $\mathrm{GmbH}$ ) and Benjamin Hammerich (ETH Zurich) presented another collaborative paper introducing a new stylometrical possibility for authorship attribution of verse texts, which has until now been limited to a few case studies. When focusing on many boolean rhythmical variables (e.g. the frequencies of stressed syllables in particular metrical positions, frequency of isosyllabic rhyme words etc.), the results may be achieved by analysing smaller text units. The first results of such analysis on examples from Czech and German poetry were described. Also, a novel way of verse analysis was introduced by Evgeny Kazartsev (National Research University Higher School of Economics in St. Petersburg) who, in co-operation with Victor Vashchenkov, has developed a multifunctional program system, which, based on text prosody, allows to construct two types of probability models of versification mechanisms in different languages - either rigid (with a nonlinear verse line filling) or looser (allowing a linear formation of verse lines). They found that the realization of typologically common systems of metric versification depends less on language features than on cultural and historical conditions in which versification developed.

Session VI started with the presentation of Jean-Louis Aroui (Paris 8 University) who discussed the question: "Why do we perceive text as lines in 
folksongs and pop songs?" This seems to be supported by alliteration, rhymes, as well as by the printed forms of lyrics. Aroui argued that the lines can be either created by text-setting or suggested by certain properties of music. This theory can be tested on different corpora of texts in different languages. Next, Mihhail Lotman (University of Tartu, Tallinn University) posed the question of the existence of autonomous laws of verse rhythm. He presented the proand counter-arguments, and demonstrated how the differentiation between different eras and meters has to be regarded and, in certain cases, the autonomous regularities of rhythm do not depend directly on language or meter. Igor Pilshchikov (Tallinn University, UCLA) examined Russian accentual verse using Mayakovsky's poetry as example. Mikhail Gasparov opposed accentual verse to dolnik - a specific Russian version of German strict stress-meter, and described the latter as a transitional form between syllabic-accentual verse to accentual verse properly. However, this definition can be argued. Pilshchikov discussed several features of dolnik and accentual verse, questioned the supposed differences between them, and demonstrated similarities (in particular, they both can add extrametrical stresses and skip metrical stresses). According to Pilshchikov, the prosodic basis of Mayakovsky's accentual verse is a sequence of metrical stresses (ictuses), rather than natural language stresses, therefore it cannot be described as "pure" accentual verse. Finally, Sergei Liapin (Voeikov Main Geophysical Observatory, St. Petersburg) discussed the differences between the rhythm of Russian lyric poetry in the second half of the 19th century and the Russian lyroepic verse of the same period (both written in iambic meter). The reason for these differences was the considerable weakening of the restriction on the syntactic closeness of the poetic line in the lyroepic verse, which led to an increase in the frequency of the rhythmic types of the line with an unstressed second foot. A quantitative analysis using Andrei Dobritsyn's method of measuring rhythmic entropy (Dobritsyn 2016) allows us to see such rhythmic diversities in different poetic texts, and can also be used for comparison of the same meter in different languages (a trial analysis on English and Russian iambic tetrameter was presented in the closing part of Liapin's paper).

Session VII started with a presentation by Andreas Keränen (University of Gothenburg) on resyllabification of words in Latin poetic meter. The wordboundaries in Latin meters are generally ignored, but according to the Luch's law the iambic word ends LH\# can't occur at certain positions in the line, the only exception being the fourth-paeon sequence LLLH\#. Lev Blumenfeld (2011) assumes that the resyllabification did not take place there and the paeon sequence was actually HLLH. However, there are some problematic fourthpaeon words in early Roman drama texts (like recipiat, operuit), which do 
not correspond with this assumption. Keränen showed that these words are amended in manuscripts and, when considering only secure readings, the remaining words are compounds of certain pre-fixes, which in the older stages of Latin were consonant-final. Therefore, their quantitative pattern might also be HLLH. Maria-Kristiina Lotman (University of Tartu) presented a paper on behalf of a study group (Anni Arukask, Kaidi Kriisa, Tuuli Triin Truusalu and Martin Uudevald, all of University of Tartu; Kristi Viiding, Under and Tuglas Literature Centre of the Estonian Academy of Sciences) on the meter and prosody of the verse texts in the Latin inscriptions of Estonian ecclesiastical space. The verse texts originated from a database of local Lutheran and Catholic pre-1918 Latin inscriptions that is under construction as a part of the project CEILE (Corpus Electronicum Inscriptionum Latinarum Estoniae). The analysis showed how despite a few prosodic and metrical errors, the hexameters and elegiac distichs follow the ancient models and standards still quite accurately, and that appeared on all the observed levels: metrical, rhythmical and prosodic. Annika Mikkel (University of Tartu) presented the statistical analysis of the occurrence of different types of cursus in Dante Alighieri's Italian prose books Vita Nuova and Convivio. She examined which type of cursus is most commonly used in both texts and brought out some differences according to the content of the chapters. A comparative analysis was performed with other 14th century authors Giovanni Boccaccio, Franco Sacchetti and Giovanni Villani. Mikhail Trunin (Tallinn University) gave a historical overview of the concept of the "semantic halo of meter" and discussed the semantics of Osip Mandelshtam's poem "Skilful Lady of Guilty Glances..." (1934) written in trochaic pentameter. According to Mikhail Gasparov, trochaic pentameter has five semantic "shades": night, landscape, love, death and the road. Mandelshtam's poem addresses most of these themes; thus the choice of meter must not have been a coincidence and it is surprising that it has not been noticed by scholars until now. Trunin emphasised that the study of form and semantics should go hand in hand ${ }^{1}$.

Session VIII began with Marina Akimova's (Lomonosov Moscow State University) presentation of the statistic description of metrics and metrical composition of Mikhail Kuzmin's polymetric poems. In the first part of her paper Akimova described the metrical features of these poems and defined the quantity and content of music polymetry in Kuzmin. In the second part she analysed the occurrence and patterns of changes of tenses in these polymetric texts, showing that in Kuzmin's poetry the grammatical expression

1 See his article "Towards the Concept of Semantic Halo" in the present volume. 
of time and meter are connected as a distinctive feature of his poetry. This could be proved by equivalent tense-meter relations in his texts, and by the extratextual material. After that, Grigori Utgof (Tallinn University) posed the question whether clausulae matter, on the example of David Samoilov's Beatrice. He suggested that the generally accepted approach to the study of metrical line types sans clausulae is applicable to comparative research, e.g. the research of poets' rhythmical preferences, yet such an approach becomes totally non-informative when the metric repertoire of a certain poetic cycle is investigated. Therefore, in these cases, the analysis should be a lot more nuanced and detail-oriented. Arina Davydova and Evgeny Kazartsev (National Research University Higher School of Economics in St. Petersburg) compared different rhythmic characteristics of early Ukranian iambic poems by Ivan Kotliarevski with some Russian iambic texts of the 18th century, and Taras Shevchenko's tetrameters with the tetrameters of his Russian contemporaries. Although Russian and Ukrainian tetrameters developed in a rather similar way, the study shows considerable differences in their rhythm. In large part, these differences arise from the fact that Russian and Ukrainian poets used different strategies in the realisation of metric schemes. Lastly, Evgeny Kazartsev and Ekaterina Nakonechnaya (National Research University Higher School of Economics in St. Petersburg) examined the prosody of poets' prose and the rhythm of verse by the example of Pushkin's The Queen of Spades. Previous studies on verse-like fragments in Pushkin's The Tales of Belkin and The Queen of Spades had given contradictory results for the hypothesis that the experience of verse writing influences prose writing. Such results are caused by a conflict in the criteria concerning the analysis of the syntagmatic integrity of "iambic" fragments. Re-examination of the prosodic characteristics of The Queen of Spades on the basis of the sytagmatic approach revealed compatible results with The Tales of Belkin, where the rhythm of prose had shown certain connections with verse. The same can be observed in Pushkin's later prose works, yet in his unfinished first novel Dubrovsky he seems to have tried to consciously diminish that influence.

The authors of this article would like to express their gratitude to all the speakers for very interesting topics, novel ideas and stimulating presentations on various aspects of metrics, as well as to the organizers of the conference. The programme and abstracts of the conference are available on the web-page of the conference ${ }^{2}$.

2 http://www.tlu.ee/en/FrontiersinComparativeMetrics3 


\section{References}

Blumenfeld, Lev 2011. Abstract Similarities between Greek and Latin Dialogue Meters. In: Lotman, Mihhail; Lotman, Maria-Kristiina (eds.), Frontiers in Comparative Prosody. Bern [etc.]: Peter Lang, 269-288.

Dobritsyn, Andrei 2016. Rhythmic entropy as a measure of rhythmic diversity (The example of the Russian iambic tetrameter). In: Studia Metrica et Poetica 3(1), $33-52$. 